\title{
UNIVERSALISMO Y RELATIVISMO EN LOS SENTIDOS FILOSÓFICOS DE "TRADICIÓN"*
}

\author{
AMBROSIO VELASCO GÓMEZ \\ INSTTTUTO DE INVESTIGACIONES FILOSÓFICAS \\ UnIVERSidAd NaCional AuTónOMa de MÉxico
}

\section{Introducción}

En distintos campos de la filosofía contemporánea existe una amplia y sólida convicción de buscar opciones a diversas modalidades del dilema entre orientaciones apriorísticas y normativas que buscan una fundamentación racional y universal para la justificación del conocimiento y acciones humanas, o bien la aceptación resignada de un relativismo contextualista que se limita a describir y explicar causalmente las diversas maneras como individuos y comunidades específicas producen, aceptan y cambian creencias, valores, instituciones, etc. Como ejemplos paradigmáticos de estas posiciones extremas, comúnmente se considera a autores como Rudolph Carnap dentro del fundacionismo universalista y a Paul Feyerabend y Richard Rorty en el extremo relativista, en el campo de la filosofía de la ciencia. ${ }^{1}$

En los esfuerzos por superar este dilema, la rehabilitación del concepto de tradición en el ámbito de las ciencias y las humanidades ha servido estratégicamente para reformular nociones de racionalidad menos estrictas y pretenciosas que las nociones universalistas, metódicas y demostrativas, pero que permiten una evaluación más apegada a las maneras como efectivamente los hombres en comunidades determinadas aceptan, cuestionan, rechazan y reemplazan creencias, métodos, prácticas, instituciones e.incluso los mismos criterios de evaluación.

Sin embargo, la rehabilitación del concepto de tradición ha producido una multiplicidad de sentidos que tiende a oscurecer la relevancia episte-

* Agradezco la lectura atenta y los valiosos comentarios que hicieron a versiones anteriores de este trabajo a Larry Laudan, Mariflor Aguilar, Lilián Alvarez y a la persona anónima que dictaminó este trabajo.

1 Leo Straus y Quentin Skinner ocuparían respectivamente posiciones también extremas en el universalismo y el contextualismo en el área de la filosofía política. (Cfr. A. Velasco "Racionalidad de las teorías políticas", en O. Nudler (comp.), La racionalidad, su poder y sus límites, Paidós, Buenos Aires, 1996, pp. 483-493.) 
mológica de este concepto, a tal grado que para algunos filósofos contemporáneos como Stephen Turner, apelar a conceptos como prácticas o tradición para fundamentar la racionalidad de las creeencias o de las acciones es apelar a nada. ${ }^{2}$

Entre los autores que reelaboran el concepto de tradición para superar el dilema mencionado puede observarse una tendencia a reincidir en algunos de los polos del dilema. Tal es el caso, por ejemplo de Karl R. Popper que tiende a defender una noción universalista de racionalidad de la tradición y en el otro extremo, en algunos aspectos, Gadamer niega la existencia de criterios para dirimir el conflicto entre interpretaciones, pese a que reconoce el alcance universal de la tradición. De manera análoga en un ámbito más acotado históricamente, Larry Laudan parece inclinarse hacia la aceptación de un criterio de progreso de aplicación universal, para toda tradición, mientras que Michael Polanyi y Thomas Kuhn parecen sostener una posición escéptica respecto a los fundamentos racionales de cambios de tradiciones.

La tendencia de estos filósofos a reflejar posiciones universalistas o relativistas no puede interpretarse como un mero fracaso de superar el dilema inicial. Por el contrario, sus posiciones universalistas o relativistas resultan mucho más moderadas que las posiciones extremas que tratan de superar. ${ }^{3}$ Uno de los propósitos de este trabajo es mostrar que los diferentes usos del concepto de tradición constituyen un avance significativo en la comprensión de la racionalidad de nuestro conocimiento y acciones. El otro propósito del trabajo es buscar una mediación y equilibrio entre los diferentes énfasis (justificacionista o historicista) de los usos del concepto de tradición en la historia y filosofía de las ciencias y en las humanidades. ${ }^{4}$

En la primera parte del trabajo analizo y comparo los sentidos de tradición de Popper y Gadamer, como concepciones que se extienden a través de toda la historia. En la segunda parte analizo críticamente las concepciones de Michael Polanyi, Thomas S. Kuhn y Larry Laudan como tradiciones históricamente limitadas y arraigadas. En la tercera parte destaco los méritos

2 Cfr. S. Turner, The Social Theory of Practices. Tradition, Tacit Knowledge and Presupositions, University of Chicago Press, Chicago, 1994, p. 100.

3 Mauricio Beuchot denominaría a estas posiciones que median entre extremos "analógicas". En su reciente libro Posmodernidad, hermenéutica y analogía, uc-Porrúa, 1996, analiza diferentes posiciones analógicas en diversas áreas de la filosofía.

4 Aun en estos ámbitos el análisis y discusión de los conceptos de tradición que se hacen en este trabajo, dista mucho de ser exhaustivo y no tiene esa pretensión. En el ámbito de la historia y filosofía de la ciencia, por ejemplo, no se discuten concepciones relativistas o contextuales extremas como las de Feyerabend y Rorty que aceptan un relativismo y escepticismo radical, o como las de Latour y Woolgar en los estudios sociales de la ciencia, que enfatizan el carácter eminentemente práctico, social y local de las tradiciones científicas. (Sobre este tipo de estudios véase Andrew Pickering (comp.), Science as Practice and Culture, University of Chicago Press, 1992.) 
y limitaciones de las concepciones de estos cinco filósofos. En las conclusiones rescato e integro aspectos de los diferentes sentidos de tradición, para sugerir una noción que supere las tendencias a reimplantar una visión (moderada) de los polos del dilema que se quiere superar.

\section{Concepciones transhistóricas de la tradición: Popper y Gadamer}

Las concepciones transhistóricas conciben la tradición como un proceso eminentemente intelectual que se extiende a lo largo de la historia. Karl R. Popper y Hans G. Gadamer sustentan esta concepción, aunque difieren sustantivamente respecto a la idea de racionalidad y progreso de la tradición.

Karl R. Popper defiende un conjunto de tesis que posteriormente serán desarrolladas por filósofos pospositivistas de la ciencia (Kuhn, Hesse, Shapere, Toulmin, Lakatos, Laudan, etc.). Entre estas tesis se puede resaltar el carácter convencional de la base empírica ${ }^{5}$ y de las reglas metodológicas, pero sobre todo la idea de que el desarrollo del conocimiento científico está condicionado por teorías, métodos, criterios y valores históricamente heredados, que orientan el planteamiento de problemas, la formulación de hipótesis y su aceptación o rechazo. Popper denomina a estos elementos heredados "tradición".

Al reconocer que la tradición es un factor fundamental para el desarrollo del conocimiento, Popper se opone a las concepciones racionalistas y empiristas de la modernidad que consideraban a la tradición como un obstáculo para la fundamentación objetiva del conocimiento en fuentes indubitables (la razón o la experiencia). ${ }^{6}$

$\mathrm{Al}$ oponer ciencia y tradición, los filósofos modernos no sólo negaron el hecho histórico de que no "podemos liberarnos totalmente de los lazos

5 Cfr. K.R. Popper, La lógica de la investigación cientifica, Tecnos, Madrid, 1973, cap. V. Es importante notar que la tesis convencionalista de los enunciados básicos observacionales ya había sido reconocida por Otto Neurath en 1932: "No hay forma de tomar oraciones protocolares concluyentemente como punto de partida de las ciencias. No hay tábula rasa. Somos como navegantes que tienen que transformar su nave en pleno mar, sin jamás poder desmantelarla en un dique de arena y reconstruirla con los mejores materiales." (O. Neurath, "Proposiciones protocolares", en A.J. Ayer (comp.), El positivismo lógico, FCE, México, 1981, p. 206.)

6 Con este reconocimiento a la relevancia epistemológica de las tradiciones intelectuales, Karl R. Popper está aceptando en parte las críticas de Michael Oakshott al racionalismo moderno y contemporáneo. De hecho la elaboración popperiana del concepto de tradición es una respuesta al artículo de Oakshott, "Rationalism in Politics", publicado originalmente en el Cambridge Journal en 1947. En este trabajo Oakshott además de cuestionar las pretensiones universalistas del racionalismo moderno y contemporáneo, defiende la importancia de la tra. dición en el ámbito del conocimiento moral y político. (Cfr. Michael Oakshott, "Rationalism in Politics", reproducido en su libro Rationalism in Politics and Others Essays, Methuen, Nueva York, 1967.) 
de la tradición" y que "la llamada liberación sólo es, realmente, un cambio de una tradición a otra". ${ }^{7}$ Además de ignorar este hecho', en sus ansias por fundamentar racionalmente el conocimiento, los filósofos perdieron de vista dos funciones epistemológicas de gran importancia que desempeñan las tradiciones: la primera de ellas es proporcionarnos conocimientos elaborados durante siglos y milenios. "Si comenzáramos todo de nuevo, entonces, al morir estaríamos en la misma etapa que Adán y Eva cuando murieron." Para progresar en la ciencia, afirma Popper, "debemos apoyarnos en los hombros de nuestros predecesores. Debemos continuar cierta tradición". ${ }^{8}$ La segunda función epistémica importante es la formación de una actitud y destreza crítica que permita al científico y al filósofo reflexionar sobre lo dado en las tradiciones, para liberarse de sus prejuicios y tabúes. Esta liberación puede darse tanto por medio de la aceptación reflexiva de elementos de la tradición o de su rechazo, también reflexivo y racional.

Al distinguir estas dos funciones epistemológicas, Popper reconoce dos tipos correspondientes de tradiciones intelectuales. Por un lado, las tradiciones concretas formadas por teorías y mitos específicos, y que transmiten conocimiento sustantivo desarrollado por generaciones pasadas, constituyen "las tradiciones de primer orden". Estas tradiciones son la principal fuente de nuestro conocimiento. Sin embargo, esto no significa que este tipo de tradición sea el fundamento del conocimiento. ${ }^{9}$ La función de fundamentación del conocimiento corresponde a otro tipo de tradición, que es más bien una metatradición transhistórica, carente de contenidos cognoscitivos específicos y que consiste más bien en una actitud y metodología críticas. Esta "tradición de segundo orden" es el racionalismo crítico, que inventaron los filósofos griegos hace más de dos mil años, y aun en nuestros días permanece sin cambios como el rasgo más importante del conocimiento científico. ${ }^{10}$ Gracias a esta tradición crítica puede superarse la actitud

7 Karl R. Popper, "Hacia una teoría racional de la tradición", conferencia pronunciada en 1949 y reproducida en su libro El desarrollo del conocimiento científico. Conjeturas y refutaciones, Paidós, Buenos Aires, 1979, p. 143.

8 Ibid., p. 152.

9 "El hecho de que, en su mayor parte, las fuentes de nuestro conocimiento sean tradicionales condena el antitradicionalismo como fútil. Pero no se debe aducir este hecho para defender una actitud tradicionalista: toda parte de nuestro conocimiento tradicional es susceptible de examen crítico y puede ser abandonada. Sin embargo, sin la tradición el conocimiento sería imposible", K.R. Popper, "Sobre las fuentes del conocimiento y de la ignorancia", en op. cit., sec. XVI, p. 37. (Esta sección del artículo corresponde a un artículo publicado por primera vez en 1959.)

${ }^{10}$ Cfr. Karl R. Popper, "Hacia una teoría racional de la tradición", en op. cit., p. 150. 
tradicionalista y dogmática y es posible vivir racionalmente en y a través de tradiciones específicas. ${ }^{11}$

Las tradiciones específicas de primer orden y la tradición universal (o transhistórica) de segundo orden no sólo cumplen funciones distintas (fuente y fundamentación del conocimiento), sino que también tienen características muy diferentes. Las tradiciones de primer orden son plurales, surgen siempre en contextos históricos específicos y cambian continuamente como resultado de la evaluación crítica que de ellas se hace desde la tradición de segundo orden. Este último tipo de tradición es única, invariable y de alcance universal. Las tradiciones específicas de primer orden son pasivas en cuanto meramente proporcionan el material para la evaluación crítica; en cambio la tradición crítica de segundo orden es activa, en cuanto realiza el escrutinio crítico de las tradiciones y de esta manera fomenta su cambio y progreso. Sin embargo, la tradición crítica no es reflexiva, no se somete a sí misma a crítica y.por ende no cambia ni evoluciona.

En el ámbito de la hermenéutica filosófica, Hans G. Gadamer también cuestiona la oposición entre razón y tradición que ha predominado en la modernidad, así como la idea misma de tradición como algo invariable, unívoco y autoritario. ${ }^{12}$ Al igual que Popper, considera que toda racionalidad se ejerce sobre contenidos históricamente cambiantes, pero a diferencia de él, Gadamer infiere de aquí que toda racionalidad tiene un carácter

11 La distinción entre tradición y tradicionalismo que establece Popper, ha sido desarrollada con mayor claridad por Edward Shils en el ámbito social y político: "El tradicionalismo no sólo es hostil a la libertad, sino también radicalmente hostil a la tradición, a la tradición vaga y flexible que aunque no incluya la tradición de la libertad al menos permite a la libertad vivir en sus márgenes de ambigüedad para crecer gradualmente y echar raíces profundas. En las sociedades oligárquicas el tradicionalismo previene el desarrollo de los elementos que pueden dar lugar al surgimiento de la libertad. En las sociedades en que la libertad está ya establecida, el tradicionalismo es el más grande enemigo de la vida civil..." (Edward Shils, The Virtue of Civility, Liberty Fund, Indianápolis, 1997, p. 116.) En el ámbito de la teoría social y de la filosofía política otros autores como Peter Winch, Michael Oakshott y Alasdair MacIntyre también rechazan el carácter dogmático que se asocia comúnmente a las tradiciones y afirman por el contrario la posibilidad de que los participantes de una tradición tengan una actitud crítica, reflexiva y racional hacia ella. En otro trabajo posterior analizaré las concepciones de estos autores de las tradiciones en el ámbito social y político, pero, como lo mencioné en la Introducción, en el presente artículo me limito a estudiar las tradiciones intelectuales en el ámbito de las ciencias y las humanidades.

12 Me parece que éste es uno de los aspectos centrales a los que se refiere Gadamer al afirmar que "la crítica de Popper al positivismo entraña ciertos temas afines a mi orientación personal". (H.G. Gadamer, "Entre fenomenología y dialéctica. Intento de una autocrítica (1985)", en Verdad y método II, Sígueme, Salamanca, 1994, p. 12.) 
contextual y no universal y abstracto. ${ }^{13}$ Esta conclusión distinta se debe a la forma como Gadamer concibe la crítica.

Gadamer también coincide con Popper en la tesis de que reflexión crítica sobre la tradición bien puede reafirmar y conservar lo dado, o bien cuestionarlo y suplantarlo. Sin embargo, a diferencia de Popper, Gadamer no considera que la evaluación crítica de lo dado en la tradición sea función de una tradición de segundo orden. Para Gadamer existe un solo orden de tradición en la que se conjugan los contenidos transmitidos y la reflexión crítica. Esta reflexión requiere siempre de una confrontación de los prejuicios heredados con otras voces de la tradición que no han sido transmitidos en el presente. La confrontación de la pluralidad de voces y perspectivas no puede resolverse, como lo pensaría Popper, a través de metodologías o criterios rigurosos y universales; por el contrario, la confrontación plural de voces ha de verse como un diálogo entre el sujeto que trata de comprender su tradición, desde una situación histórica determinada y los textos u obras de la tradición que tienen voz propia. Todo aquello que pueda ser comprendido y confrontado por el sujeto forma parte de la tradición. Incluso el intérprete mismo es una instancia de la tradición y su comprensión "es un desplazarse uno mismo hacia un acontecer de la tradición". ${ }^{14}$ En este sentido la comprensión de la tradición, es también una conversación entre el intérprete y los elementos significativos de la tradición (textos, obras de arte, vestigios, monumentos, etc.), a través de la cual sus voces se hacen presentes. Este traer al presente las voces del pasado que se transmiten en la tradición es para Gadamer una fusión de los horizontes hermenéuticos plurales (del presente y del pasado) que posibilita explicitar y evaluar los prejuicios que el intérprete había heredado, promoviendo su cuestionamiento y crítica. ${ }^{15}$ Pero habría que preguntarse ¿cómo es posible que conceptos y juicios del pasado distante puedan compararse con ideas y prejuicios del presente? Esto es posible gracias a que Gadamer reconoce una conmensurabilidad universal entre manifestaciones de cualquier momento histórico de la tradición, no importando cuán diferentes sean:

13 "la idea de una razón absoluta no es una posibilidad de la humanidad histórica. Para nosotros, la razón sólo existe como real e histórica, esto es, la razón no es dueña de sí misma sino que está siempre referida a lo dado en lo cual se ejerce" (H.G. Gadamer, Verdad y método, Sígueme, Salamanca, 1977, cap. IX, p. 343).

14 Ibid., p. 360.

15 "El horizonte del presente está en un proceso de constante formación en la medida en que estamos obligados a poner a prueba constantemente todos nuestros prejuicios. Parte de esta prueba es el encuentro con el pasado y la comprensión de la tradición de la que nosotros mismos procedemos [...] Comprender es siempre el proceso de fusión de estos presuntos horizontes existentes para sí mismo." (H.G. Gadamer, Verdad y método, Sígueme, Salamanca, 1977, p. 377.) 
Cuando nuestra conciencia histórica se desplaza hacia horizontes históricos, esto no quiere decir que se traslade a mundos extraños, a los que nada vincula con el nuestro; por el contrario todos ellos juntos forman ese gran horizonte que se mueve por sí mismo y que rodea la profundidad histórica de nuestra autoconciencia más allá de las fronteras del presente. En realidad es un único horizonte el que rodea cuanto contiene en sí misma la conciencia histórica. ${ }^{16}$

Para Gadamer, el conocimiento que resulta de la comprensión de la tradición no es una teoría general metódicamente demostrable; se trata más bien de un conocimiento práctico y prudencial, cuya validez depende de las circunstancias específicas en las que se aplica (phronesis aristotélica). No hay por lo tanto criterios generales ni procedimientos metodológicos estables y universales. ${ }^{17}$

Así, pues, Gadamer difiere radicalmente de la visión popperiana de la racionalidad metódica demostrativa y universal, a pesar de que reconoce junto con Popper el alcance universal de la tradición; pero en Gadamer la tradición es más compleja que en Popper, ya que está constituida tanto por teorías e interpretaciones sustantivas como por criterios, deliberaciones y juicios prudenciales a través de los cuales se someten a evaluación los contenidos e interpretaciones de la tradición, se incrementa la pluralidad de voces y puntos de vista y, de esta manera, se promueve el progreso de la tradición a través de un diálogo cada vez más inclusivo y de mayor alcance. ${ }^{18}$

\section{Concepciones históricamente arraigadas de tradiciones}

En este apartado analizaré las concepciones de tradición de Polanyi, Kuhn y Laudan como tradiciones específicas e históricamente acotadas.

Michael Polanyi cuestiona fuertemente las concepciones predominantes de la objetividad del conocimiento objetivo que se fundamentan en un mero análisis lógico, semántico y metodológico de las teorías científicas. Para

16 Ibid., p. 375.

17 "La reflexión hermenéutica se limita a abrir posibilidades de conocimiento que sin ella no se percibirían. No ofrece un criterio de verdad" (H.G. Gadamer, "Réplica a Hermenéutica y crítica de la ideología", en Verdad y método II, Sígueme, Salamanca, 1994, p. 254).

18 "Así debe entenderse la pretensión de universalidad que corresponde a la hermenéutica. La comprensión va ligada al lenguaje [...] pero el vivir en el lenguaje no es relativismo, porque no nos condena a ese lenguaje concreto [...] En principio toda lengua en la que vivimos es inagotable, y es un craso error concluir de la existencia de diversas lenguas que la razón está escindida. Lo contrario es lo cierto. Justamente, por la vía de la finitud, la particularidad de nuestro ser, visible también en la diversidad de lenguas, se abre el diálogo infinito en la dirección de la verdad que somos." (Hans G. Gadamer, "La universalidad del problema hermenéutico (1966)", en Verdad y método II, p. 223.) 
comprender la validez propia de las creencias, Polanyi considera indispensable referirse a un conjunto de conocimientos y habilidades confiables que los científicos han adquirido y que son esenciales para elaborar el conocimiento científico. Así, a diferencia de la mayoría de los filósofos de la ciencia de mediados de siglo, Polanyi enfoca su análisis en el "conocimiento personal" que el científico posee y en el tipo de actividades que tal conocimiento le permite desempeñar de manera diestra. ${ }^{19}$

El conocimiento personal que permite a un científico desempeñar adecuadamente su trabajo está constituido principalmente por ciertos saberes y destrezas que ha aprendido y desarrollado a través de una larga y continua práctica en contacto directo con sus maestros. Estos saberes y destrezas son en su gran parte tácitos y no explícitos. Por ello, no es posible describirlos de manera articulada en proposiciones a manera de reglas, prescripciones o máximas. ${ }^{20}$ Es un conocimiento en buena medida inefable que se muestra en la práctica y que se aprende por imitación. Es precisamente este tipo de conocimiento y su forma de transmisión lo que constituye para Polanyi la tradición. En este sentido, Polanyi afirma que "una sociedad que quiere preservar cierto cúmulo del conocimiento personal tiene que someterse a la tradición". ${ }^{21}$

Además del carácter eminentemente práctico, tácito y local de las tradiciones, Polanyi señala también que las tradiciones ostentan cierta autoridad ante sus practicantes. ${ }^{22} \mathrm{El}$ conocimiento, destrezas y criterios que la tradición transmite orienta, de manera significativa pero no determinante, la selección de los problemas y hechos relevantes, la creación de hipótesis (función heurística) y la forma de argumentación a través de la cual los científicos tratan de persuadir a sus colegas en sus controversias. Pero esta

19 Refiriéndose a su libro Personal Knôwledge, Polanyi declara que "El propósito de este libro es mostrar que la objetividad completa que normalmente se atribuye a las ciencias exactas es una ilusión y de hecho un falso ideal. Pero no trataré de repudiar la objetividad estricta como un ideal sin ofrecer otro sustituto que considere más digno de aceptación inteligente; a este sustituto lo he denominado conocimiento personal" (Michael Polanyi, Personal Knowledge, Routledge and Kegan Paul, Londres, 1962, p. 18. (Publicado originalmente en 1958)).

20 "Un arte que no puede especificarse en detalle no puede ser transmitido por prescripción, porque no existe para ese arte prescripción alguna. Únicamente puede ser transmitido del maestro al aprendiz por medio del ejemplo. Esto restringe el ámbito de difusión al contacto personal, y por ello, el saber artesanal tiende a sobrevivir en tradiciones locales estrechamente circunscritas [...] En este sentido, mientras que los contenidos articulados de la ciencia se han enseñado en cientos de nuevas universidades en todo el mundo, el arte no especificable de la investigación científica aún no ha penetrado en muchas de esas universidades" (ibid., p. 53).

21 Loc. cit.

22 "Cuando hablo de ciencia reconozco tanto su tradición como su autoridad organizada y niego que las rechace totalmente, puede decirse que sea un cientifico que tenga una comprensión y apreciación adecuadas de la ciencia" (ibid., p. 164). 
función selectiva heurística y argumentativa de los contenidos de la tradición se convierten en verdaderas pasiones intelectuales de los científicos. En especial la pasión heurística, que es "la principal fuente de originalidad" $\mathrm{y}$ "la fuerza que impele a abandonar un marco de interpretación aceptado y nos compromete a cruzar un abismo lógico para utilizar un nuevo marco"23 puede llevar a confrontar, cuestionar y eventualmente transformar componentes esenciales de una tradición determinada. En este sentido, a pesar de que las tradiciones científicas tienen autoridad y permanecen durante largo tiempo, no son incuestionables ni estáticas. Por el contrario, el mismo ejercicio del conocimiento personal guiado por la pasión heurística que formula y resuelve nuevos problemas, conducen paulatinamente a cambios de gran significación en las tradiciones científicas. ${ }^{24}$

Si bien Polanyi reconoce la importancia de las controversias en las tradiciones científicas, reconoce también las graves dificultades que surgen cuando las controversias involucran una ruptura con las creencias fundamentales de la tradición en cuestión. Quienes participan en tales controversias "piensan diferente, hablan diferente lenguaje, viven en un mundo diferente..." y en la medida en que el sistema que se opone a una determinada tradición establecida representa un determinando estilo de razonamiento "no puede convencerse a otros a través de argumentos formales" sino que "la demostración debe sustituirse por otras formas de persuasión que puedan inducir una conversión"25 a la nueva concepción. Se trata de una conversión precisamente por que es un acto de modificación de la forma de percibir, interpretar y juzgar de las personas a través de un cambio de sus simpatías intelectuales y no como resultado de un proceso de convencimiento o demostración metódica. Estas experiencias de conversión a un nuevo sistema necesariamente involucran un cambio de los saberes y habilidades tácitos del conocimiento personal para que resulten eficientes en los nuevos marcos interpretativos. De manera optimista Polanyi considera que el desarrollo del conocimiento personal es progresivo y por ello las tradiciones científicas progresan en el curso de la historia.

A diferencia de Popper y más afín a la perspectiva de Polanyi, Kuhn rechaza la idea de que la crítica y transformación de una tradición científica se deba a una meta-tradición universal que permite a los individuos evaluar críticamente lo transmitido por las tradiciones específicas. Para Kuhn existe un sólo tipo de tradiciones que involucran conceptos, teorías, presupuestos ontológicos y metodológicos, así como criterios, actitudes, valores, destrezas

23 P. 159.

24 "Una concepción razonable de la ciencia debe incluir visiones en conflicto y admitir cambios en las creencias y valores fundamentales de los cientificos." (Ibid., p. 164.)

25 Ibid., p. 151. 
y prácticas a través de las cuales se evalúan las hipótesis y teorías. Con una clara influencia de Polanyi, Kuhn afirma que dentro de una tradición establecida, los miembros de las comunidades científicas plantean problemas, cuyas posibles soluciones generan controversias y acuerdos. Algunas de estas controversias llegan a producir un cuestionamiento y transformación de los fundamentos de esa tradición. ${ }^{26}$ Mientras se mantienen los presupuestos fundamentales de una tradición, es posible que las controversias se resuelvan a través de un convencimiento racional entre los defensores de diversas interpretaciones de los principios fundamentales de la tradición en cuestión. Pero cuando se rompe el consenso en los presupuestos conceptuales, teóricos, metodológicos y axiológicos de una tradición no es posible el convencimiento racional entre las partes en conflicto. La única manera de restablecer el consenso es por medio de una conversión de los defensores de la antigua tradición a nuevos esquemas teóricos y conceptuales que resultan inconmensurables con las anteriores. Así pues, al igual que Polanyi, Thomas Kuhn reconoce dos diferentes procesos comunicativos para dirimir controversias, el convencimiento tendiente a la demostración en las controversias internas en una misma tradición y la conversión persuasiva en controversias entre diferentes tradiciones. ${ }^{27}$

Si bien Kuhn coincide con Popper sobre el hecho de que los científicos tienen que compartir valores y normas epistémicas para el establecimiento de consensos a través de argumentos que convenzan al oponente, Kuhn considera que estas normas y valores epistémicos convergentes no constituyen reglas algorítmicas para resolver las controversias, de manera unívoca. Se trata más bien de normas permisivas que restringen o ponen márgenes a la discusión y argumentación. ${ }^{28}$ En este sentido la racionalidad en la elección de teorías dentro de una tradición se acerca más a la deliberación moral

26 "Una y otra vez el intento constante por dilucidar la tradición vigente termina por producir uno de esos cambios en la teoría fundamental, en la problemática y en las normas científicas." (T.S. Kuhn, "La tensión esencial: tradición e innovación", en Tensión esencial, FCE, 1982, p. 257.)

27 Refiriéndose a las controversias en periodos de revolución científica, Kuhn afirma que "la superioridad de una teoría sobre otra es algo que no puede demostrarse en el debate. En cambio, como he insistido, cada bando mediante la persuasión, debe tratar de convertir al otro" (Thomas S. Kuhn, La estructura de las revoluciones científicas, FCE, México, 1982, Posdata, p. 303).

${ }^{28}$ Este aspecto de la concepción kuhniana de la racionalidad se ha desarrollado con detalle por Ana Rosa Pérez Ransanz en su artículo "Racionalidad sin fundamentos", en León Olivé y Luis Villoro (comps.), Filosofía moral, educación e historia. Homenaje a Fernando Salmerón, UNAM, 1996. 
o política sobre asuntos prácticos (phronesis) y menos a la demostración metodológica de la verdad o falsedad de tesis teóricas (episteme) ${ }^{29}$

También a diferencia de Popper y más a tono con la visión de Polanyi, Kuhn no centra su análisis de la racionalidad de la evaluación de las teorías y presupuestos en las decisiones de los científicos considerados individualmente; más bien, enfoca su atención a los procesos dialógicos en la comunidad científica. ${ }^{30}$ Las tradiciones acontecen y devienen a través de los procesos comunicativos en las comunidades científicas, y no por las meras decisiones de cada uno de los científicos. Las tradiciones científicas son la fuente de racionalidad de estos procesos comunicativos en cuanto proveen lenguaje, criterios, valores y normas epistémicas comunes y relativamente estables. Fuera de estas tradiciones específicas no hay lenguaje, ni criterios de racionalidad que permitan evaluar comparativamente los contenidos cognoscitivos de tradiciones Jistintas. Por ello, no es posible determinar si un cambio de tradición a otra, una revolución científica, representa un progreso o no. ${ }^{31}$ En este sentido Kuhn se separa de Gadamer, de Popper y de Polanyi y parece adoptar una posición relativista, posición que provocó las más fuertes objeciones de filósofos de la ciencia como Popper, Lakatos, Toulmin y Laudan, entre otros. Así pues, al enfatizar el arraigo histórico y los aspectos sociales de las tradiciones, Kuhn, ante los ojos de los filósofos de la ciencia, perdió de vista la racionalidad del cambio científico. Los filósofos de la ciencia posteriores a Kuhn (Lakatos, Shapere, Hacking, Laudan) se propusieron dar cuenta de la racionalidad del cambio de tradiciones históricamente arraigadas, sin apelar a tradiciones transhistóricas de alcance universal. En esta línea, Larry Laudan ofrece la más clara reformulación del concepto de tradición.

Larry Laudan considera que toda tradición de investigación está constituida por: un conjunto de teorías específicas en continuo proceso de revisión

29 Es importante anotar que la tesis de que la racionalidad de la ciencia reside ante todo en una racionalidad práctica de carácter ético y no epistémico, es un punto importante de convergencia con la hermenéutica filosófica de Gadamer. Sin embargo, desde principios de siglo, Pierre Duhem expuso esta idea con claridad cuando afirmaba que "la lógica no determina con precisión estricta cuándo una hipótesis inadecuada debe de dar paso a una hipótesis más fructífera [...] el reconocimiento del momento adecuado de tal cambio depende del buen sentido..." (Cfr. Pierre Duhem, The Aim and Structure of Physical Theory (1906), Atheneum, Nueva York, 1977, cap. VI, sec. 10, p. 218.)

30 "Estrictamente hablando, es el grupo profesional, y no el científico individual, el que debe mostrar simultáneamente estas características [tradicionalista e iconoclasta] [...] Dentro del grupo algunos individuos serán tradicionalistas, otros iconoclastas, y en consecuencia sus aportaciones diferirán." (Ibid., p. 251.)

31 Al respecto Barry Barnes afirma: "No hay nada que haga las veces de anclaje, estable y esencial, para la evaluación comparada. Las revoluciones separan formas inconmensurables de vida científica." (Barry Barnes, T.S. Kuhn y las ciencias sociales, FCE, 1986, p. 37.) 
y reconstrucción; un conjunto de presupuestos ontológicos que especifican el tipo de objetos y procesos que constituyen el campo de estudio de una disciplina; y un conjunto de presupuestos metodológicos y epistemológicos que acotan los procedimientos legítimos para la formulación y solución de problemas, así como los estándares para evaluar las soluciones. ${ }^{32}$

Estos presupuestos ontológicos y epistemológicos cumplen funciones fundamentales en la práctica científica, tanto en relación con la justificación de teorías como con la construcción heurística de hipótesis:

Las tradiciones de investigación pueden justificar muchas de las afirmaciones que hacen sus teorías; pueden servir para declarar inadmisibles ciertas teorías porque son incompatibles con la tradición de investigación; pueden influir en el reconocimiento y evaluación de los problemas empíricos y conceptuales de sus teorías componentes, y pueden proporcionar directrices heurísticas para la creación o modificación de teorías específicas. ${ }^{33}$

Larry Laudan reconoce que los estudios históricos de la ciencia han mostrado que los valores científicos y los criterios de evaluación cambian junto con la dinámica de las tradiciones $\mathrm{y}$, por lo tanto, resulta insostenible la idea popperiana de una metatradición racional. ${ }^{34}$ No obstante, el reconocimiento de la variedad históricamente cambiante de los criterios evaluativos inherentes a cada tradición no conduce a Laudan a afirmar la incomensurabilidad entre tradiciones, como en el caso de Kuhn, ni tampoco a una posición relativista. El modelo filosófico que propone Laudan posibilita comparar tradiciones distintas, a pesar de que cada tradición tenga presupuestos teóricos, ontológicos y epistemológicos diferentes. La comparación entre tradiciones se realiza en función del conjunto de problemas empíricos y conceptuales $^{35}$ que las teorias de cada tradición pueden resolver. Laudan

32 Cfr. Larry Laudan, Progress and Its Problems, University of California, 1977, cap. III. Hay traducción al español: El progreso y sus problemas, Ediciones Encuentro, España, 1986. (Las citas son tomadas de esta traducción.)

33 Ibid., p. 131.

34 "Una extensa información a este respecto, pone vivamente en claro que las opiniones de la comunidad científica acerca de cómo poner teorías a prueba y acerca de lo que cuenta como evidencia han cambiado a lo largo de la historia [... ] resulta anacrónico juzgar la racionalidad de la labor de un Arquímides, un Newton o un Einstein preguntando si armoniza con la metodología contemporánea de un Popper o un Lakatos." (Larry Laudan, "Un enfoque de solución de problemas al progreso científico", en Ian Hacking (comp.), Revoluciones científicas, FCE, México, 1985, p. 280.)

35 Laudan señala que la mayoría de los filósofos de la ciencia no han prestado suficiente atención a los problemas conceptuales. Este tipo de problemas se originan por incoherencias intra o interteóricas o bien incongruencias entre los presupuestos ontológicos, epistemológicos y metodológicos y la evidencia empírica que se construye para aceptar o rechazar teorías en 
observa que en esta evaluación no sólo debe considerarse retrospectivamente el cúmulo de problemas empíricos ya resueltos (contexto de aceptación), sino también prospectivamente, deben tomarse en cuenta los problemas potenciales que en el futuro se puedan resolver (contexto de búsqueda prospectiva). De esta manera Laudan reconoce explícitamente que la capacidad heurística de una tradición constituye una instancia para su evaluación. Este reconocimiento implica un rechazo a la distinción estándar entre contexto del descubrimiento y contexto de justificación.

En. suma, Laudan elabora una interesante tipología de problemas que enfrentan y buscan resolver las tradiciones científicas: en cuanto a su naturaleza, los problemas pueden ser empíricos o conceptuales; y en cuanto al carácter de la solución, los problemas pueden ser satisfactoriamente resueltos, potencialmente resolubles o no resueltos. Finalmente respecto a los problemas no resueltos en una tradición, Laudan distingue las anomalías como aquellas que han sido resueltas exitosamente por otra tradición alternativa. A pesar de que estas anomalías no refutan la teoría en cuestión, constituyen una fuerte razón para inclinar la balanza hacia la teoría alternativa que sí lo resuelve. A través de esta compleja tipología de problemas es posible evaluar de manera objetiva y comparativa el progreso de las tradiciones de investigación.

Entre los factores que más promueven el progreso de las tradiciones, Laudan destaca los debates entre diferentes teorías de una misma tradición, y los conflictos externos, entre tradiciones distintas. Aquí es importante observar que a diferencia de Kuhn, Laudan reconoce la coexistencia de tradiciones diversas de investigación y, sobre todo, que "las confrontaciones dialécticas son esenciales para el crecimiento y mejora del conocimiento científico". ${ }^{36}$ Así pues, el diálogo plural entre teorías y tradiciones, promueve el cambio y progreso científico. Este progreso no es lineal, ni acumulativo sino que responde a diferentes fines epistémicos (corroboración y descubrimiento) diferentes problemas (empíricos y conceptuales). Esto implica que la racionalidad presupuesta en el cambio de tradiciones, es más compleja que lo que pensaron filósofos como Popper y Lakatos, pero, en última instancia, el mantenimiento o cambio de tradiciones depende de una decisión de los científicos en función de un cálculo global de pérdidas y ganancias en la formulación y solución de los diversos tipos de problemas. Este cálculo no

competencia. En este sentido, los problemas conceptuales representan una reflexión crítica sobre el tipo de solución a problemas empíricos que resulta aceptable en una determinada tradición. (Cfr. Larry Laudan, "Un enfoque de solución de problemas al progreso científico", en Ian Hacking (comp.), Las revoluciones científicas, FCE, México, pp. 277-278.)

36 Larry Laudan, Beyond Positivism and Relativism. Theory, Method and Evidence, Westview Press, 1996, p. 85. 
es una mera suma y resta de los logros y fracasos de las teorías de una tradición al compararse con sus rivales. Se trata de una evaluación en la que intervienen consideraciones pragmáticas retrospectivas y consideraciones epistémicas prospectivas. ${ }^{37}$ Estos dos tipos de consideraciones pueden entrar fácilmente en tensión, cuya solución escapa a cualquier regla metodológica o criterio epistémico unívoco. Por esta razón, la evaluación de una tradición en comparación con sus rivales tiene ante todo un carácter prudencial y no algorítmico.

\section{Pertinencia epistemológica del concepto de tradición}

En los autores que hemos discutido, el concepto de tradición tiene las siguientes connotaciones:

Está constituido por textos, prácticas e instituciones que transmiten sistemas de creencias (hipótesis, principios, teorías, interpretaciones), así como habilidades, técnicas, metodologías, criterios de racionalidad y valores que permiten desarrollar y evaluar los conocimientos y prácticas transmitidos en la tradición, y en algunos casos (Laudan y Popper) permite evaluar tradiciones distintas.

Las tradiciones admiten una pluralidad limitada de teorías e interpretaciones. Al acotar las teorías que son razonablemente discutibles, las tradiciones ejercen una función normativa que señala lo permisible pero no prescribe lo verdadero o lo necesario. En este sentido las tradiciones son flexibles.

Las tradiciones se extienden a lo largo de periodos extensos (siglos o incluso milenios) y en su desarrollo se combina el cambio y la permanencia de varios de sus elementos componentes.

Por lo común, el cambio de las tradiciones es racional y progresivo, de acuerdo con los valores y criterios propios de la tradición. Toda evaluación sobre la racionalidad de creencias y acciones debe hacerse en el contexto de alguna tradición y de acuerdo con sus criterios y valores.

El cambio progresivo y racional de toda tradición consiste en buena medida en la explicitación, elucidación y crítica de algunos presupuestos tácitos de diversa índole (epistemológicos, metodológicos, metafísicos, prácticos, teóricos, morales, etc.), que han sido transmitidos por la tradición y aceptados por sus miembros sin cuestionamiento. La reflexión crítica puede tanto confirmar la autoridad de ciertos elementos de la tradición como desecharlos y sustituirlos.

37 "Otra manera de establecer la diferencia entre juicios pragmáticos y epistémicos es notar que los primeros pueden ser tratados como completamente retrospectivos, mientras que los segundos tienen un aspecto fundamentalmente prospectivo." (lbid., p. 149.) 
En suma, el concepto de tradición es utilizado por los cinco filósofos para reformular una noción de racionalidad del conocimiento que en alguna medida toma en cuenta la actividad de las personas dentro de comunidades que tienen una determinada identidad social e histórica.

Más allá de estos sentidos básicos comunes, los autores difieren respecto a los alcances de la tradición, la mayor o menor importancia de los aspectos prácticos o teóricos, de lo implícito y lo explícito, del carácter constitutivo o instrumental de las tradiciones, asi como a la concepción algorítmica o prudencial de la racionalidad de las tradiciones y a la naturaleza descriptiva o normativa del estudio de tal racionalidad. Al considerar estas diferencias, podemos ver que los filósofos que hemos discutido tienden a adoptar posiciones opuestas hacia algunos de los polos del dilema universalismo normativo-contextualismo descriptivo que tratan de superar.

Respecto al alcance de las tradiciones, a su extensión en el tiempo, Popper y Gadamer sostienen una concepción universalista. Para Popper la tradición más importante, la metatradición del racionalismo crítico, se originó en la antigua Grecia y se mantiene sin cambio alguno hasta nuestros días (a diferencia de las tradiciones especificas que continuamente cambian y progresan). Para Gadamer, la tradición se extiende indefinidamente hacia el pasado y hacia el futuro. Sin embargo, y a diferencia de Popper, Gadamer considera que todos los prejuicios incluyendo los epistémicos, que conforman la tradición son cuestionables y pueden cambiar.

Si bien Popper y Gadamer conciben una tradición universal, la concepción de la racionalidad es muy distinta. Para Popper la racionalidad es ante todo una actitud crítica que se reduce a un criterio epistemológico (refutabilidad empírica) y a una metodología básica (refutación de hipótesis por modus tollens). Se trata de una racionalidad restringida, muy cercana al ideal demostrativo de los neopositivistas que excluyen otras formas de racionalidad que la historia de las ciencias ha mostrado que son sumamente relevantes. En este sentido, el concepto de tradición (de segundo orden) de Popper parece ser un mero artificio persuasivo para disfrazar una posición universalista, justificacionista, algorítmica y eminentemente normativa.

En el lado opuesto, Gadamer rechaza toda pretensión de universalidad de criterios y metodologías para dirimir la validez de interpretaciones en competencia. Es más, parece que en algunos de sus textos rechazaría toda metodología y criterio de verdad, remitiendo la elección de interpretaciones a una cuestión de juicio prudencial, para cada caso concreto, en circunstancias determinadas. Frente a la concepción restringida de racionalidad de Popper, la visión gadameriana de racionalidad práctica y prudencial resulta un correctivo adecuado, pero precisamente un correctivo. Gadamer parece limitarse a una reflexión sobre qué es lo que sucede en la comprensión, 
cómo se confrontan prejuicios establecidos con significados olvidados en el pasado, y cómo decide el intérprete respecto a estos conflictos. Esta reflexión hermenéutica es sumamente importante para corregir concepciones rígidas y universalistas de racionalidad, pero esta crítica no tiene por qué excluir, ni soslayar esfuerzos por reconstruir metodologías y criterios más flexibles que permitan evaluar las decisiones prudenciales de los hombres en distintos campos del conocimiento y de la actividad humana.

El acierto de Gadamer de subrayar el carácter práctico de toda racionalidad humana se ve también opacado por su concepción universalista de la tradición, dentro de la cual todo en principio puede tornarse conmensurable y comprensible.

Esta visión demasiado optimista de la conmensurabilidad universal en la tradición choca con los argumentos de carácter histórico que Polanyi y Kuhn han expuesto. Además, el optimismo de Gadamer tiene implicaciones serias respecto a las condiciones de posibilidad de desarrollo racional de la tradición que él mismo ha señalado. Recordemos que la pluralidad de voces y perspectivas distantes a la propia situación del intérprete es una condición necesaria para evaluar críticamente nuestros prejuicios. En la medida en que todos los elementos que se confrontan resultan de entrada totalmente conmensurables, se admite un núcleo semántico común y familiar, de tal manera que la crítica es siempre una crítica interna, sin los grandes cuestionamientos y retos que han señalado Polanyi, Kuhn y Laudan en las controversias entre tradiciones distantes y parcialmente incomensurables.

Por otro lado, en el ámbito de las tradiciones históricamente arraigadas, donde hemos ubicado a Polanyi, Kuhn y Laudan, las posiciones opuestas del dilema también parecen replicarse, aunque de manera más moderada. Estos autores son mucho más receptivos a los aportes de la historia de la ciencia y, por ello, sus conceptos de tradición tienen connotaciones más contextuales y mejor fundamentadas en los aportes de la historia. No obstante, sus respectivas nociones de racionalidad de las tradiciones son bastante diferentes.

Polanyi ubica la racionalidad de la ciencia en los saberes y habilidades tácitos del conocimiento personal, así como en las pasiones heuristicas y persuasivas que orientan la actividad de los científicos hacia la realización de valores fundamentales (relevancia, originalidad, poder explicativo, consenso). La racionalidad de la ciencia descansa en un equilibrio entre el conocimiento tácito de las tradiciones científicas y las pasiones intelectuales que promueven el cambio de las tradiciones, asegurando así una continuidad progresiva, pero como en ningún otro caso Polanyi valora los aspectos prácticos implícitos de las tradiciones científicas.

Kuhn tampoco ubica la racionalidad en un principio o criterio metodológico claramente formulable y aplicable, sino que la sitúa en los procesos 
comunicativos y deliberativos de las comunidades científicas, que llegan a producir consensos entre sus miembros sobre la aceptación y rechazo de teorías e hipótesis. Kuhn no aceptaría cualquier consenso como racionalmente fundado, pero tampoco aceptaría que los procesos metodológicos puedan decidir concluyentemente los debates y controversias. Entre los criterios y metodologías universales, por un lado y la ausencia de todo principio y criterio, Kuhn apela a las tradiciones —entendidas como un conjunto de conceptos, presupuestos, normas, valores, prácticas y criterios explícita o tácitamente aceptados por los miembros de las comunidades científicaspara explicar cómo es posible llegar a acuerdos racionalmente fundados y cómo esos acuerdos llegan a desarticularse. Para Kuhn, al igual que para Polanyi, los elementos constitutivos de la racionalidad de la tradición no pueden ser desincorporados o explicitados totalmente de las prácticas comunicativas o deliberativas, ni tampoco es posible reconstruir la relación causal o lógica de esos presupuestos con las tesis que cada individuo sustenta, ni con los acuerdos a los que colectivamente arriban.

En cuanto que las tradiciones tienen una vida históricamente acotada y no existe metatradición alguna que sirva de fundamento común ni de mediación entre tradiciones distintas, se trata de una racionalidad históricamente limitada o de un relativismo moderado, dentro de los márgenes de cada tradición.

En Larry Laudan el concepto de tradición se aleja del universalismo popperiano, pero también toma una mayor distancia respecto al relativismo de Kuhn. Laudan reconoce que en las ciencias no existen criterios transhistóricos para evaluar teorías. Nos previene contra el anacronismo de utilizar criterios filosóficos del siglo xx para analizar la racionalidad de teorías de siglos pasados. Cada teoría debe evaluarse en términos de los presupuestos ontológicos y metodológicos de la tradición a la que pertenece. A diferencia de Kuhn y de Polanyi, Laudan reconoce la posibilidad de diálogo, debate y convencimiento racional no sólo en el interior de una tradición de investigación, sino también entre tradiciones distintas. Gracias a este diálogo es posible evaluar una determinada teoría o tradición desde los estándares de otra tradición, sin necesidad de presuponer metatradición alguna. En esta dinámica de los debates internos y externos Laudan encuentra un factor fundamental del progreso racional de las tradiciones de investigación conforme a una noción universal de progreso, que aunque pueda interpretarse de diferentes formas en tradiciones distintas, tiene un significado común: incrementar la fiabilidad o temple empírico de las teorías para incrementar la eficiencia en la resolución de problemas. En función de esta meta es posible comparar y evaluar distintas tradiciones que se suceden diacrónica o coexisten sincrónicamente. Es más, gracias a esta noción eficientista de progreso es 
posible que los individuos puedan escoger libremente trabajar en una u otra tradición, o incluso en varias tradiciones simultáneamente. En este sentido Laudan no concibe a las tradiciones de investigación como constitutivas de las comunidades científicas como lo harían Polanyi y Kuhn, sino como opciones instrumentales para realizar con mayor eficiencia el fin propio de la ciencia: la resolución de problemas en términos de buenas explicaciones y predicciones. La racionalidad de las tradiciones de investigación es ante todo una racionalidad instrumental de medios (variables) respecto a los fines (fijos) y las tradiciones son ante todo procesos intelectuales donde las prácticas no tienen la centralidad que le asignan Gadamer, Polanyi y Kuhn.

Así pues, por un lado, el concepto de tradición en Laudan representa un desarrollo y progreso en el giro contextualista de Kuhn, especialmente en lo relativo al reconocimiento de las soluciones racionales de las controversias entre diferentes tradiciones; pero, por otro lado, su concepto de tradición está supeditado a una noción universalista de progreso, cercana a la idea sostenida por Popper.

\section{Conclusiones}

En una representación esquemática de las diversas concepciones de tradición de los autores estudiados tendríamos el siguiente mapa:

(Positivismo lógico) • Universalismo

Popper •

- Gadamer

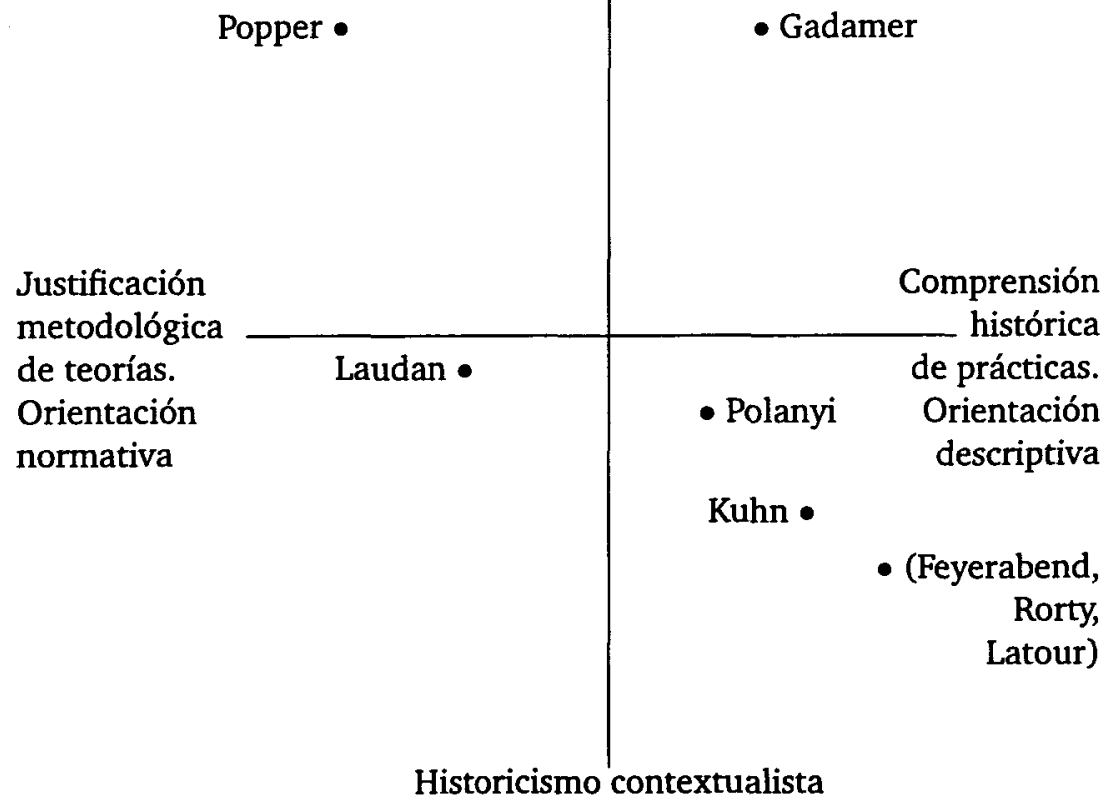


En la parte superior izquierda del esquema he situado al positivismo lógico simplemente como una referencia más o menos obvia de una posición extrema de universalismo metodológico normativo. ${ }^{38}$ Cerca de esta posición he ubicado a Popper y en el lado opuesto, pero también en la parte superior del esquema, se puede situar a Gadamer, Popper sostiene de manera apriorística una posición universalista en cuanto sostiene que la tradición del racionalismo crítico es una condición necesaria para el progreso racional de la ciencia. El universalismo de Gadamer es distinto en cuanto que no asume una tradición determinada como la tradición universal, sino más bien considera que hay un proceso de convergencia de interpretaciones históricamente acotadas en una tradición de alcance cada vez más incluyente.

Las concepciones de Popper y Gadamer sobre la tradición de alcance universal también se oponen en cuanto a la relevancia de los estudios históricos de tradiciones específicas para la elucidación de los criterios de racionalidad: para Popper los principios epistemológicos y metodológicos del racionalismo crítico son inmunes a los estudios históricos y sociales de la ciencia, mientras que para Gadamer no hay criterios ni metodologías más allá del juicio prudencial que en cada caso especifico se realice.

En la parte inferior del esquema hemos ubicado a las concepciones históricamente acotadas de las tradiciones de Larry Laudan, Thomas S. Kuhn y Michael Polanyi (además de la referencia a los autores entre paréntesis como casos extremos de relativismo descriptivista). ${ }^{39}$ Estos tres autores también se oponen respecto a la importancia del análisis histórico y sociológico, aunque esta oposición es mucho más moderada que en el caso de Popper y Gadamer: para Polanyi y Kuhn los criterios y metodologías son siempre internos a tradiciones específicas y no ofrecen elucidación de la racionalidad del cambio de una tradición a otra. Estos cambios simplemente acontecen como resultado de procesos de conversión persuasiva entre los miembros de diversas tradiciones. A diferencia de Kuhn y Polanyi, Laudan al mismo tiempo que toma en serio los estudios históricos de las ciencias y reconoce el carácter histórico de los criterios metodológicos, construye un concepto general de progreso para evaluar tradiciones en competencia, concepto que está por en-

38 Lo he puesto entre paréntesis precisamente porque los representantes del positivismo lógico no se han estudiado en este trabajo. Desde luego no todos los positivistas lógicos tienen una posición homogénea. Así por ejemplo, entre Carnap y Neurath hubo fuertes diferencias respecto al carácter convencional o naturalista de los términos observacionales. (Véase para ello el artículo de 0 . Neurath "Proposiciones protocolares".) Pero para el efecto de este esquema y como simple referencia de posiciones extremas de univeralismo metodológico no es necesario analizar estas diferencias. Esta observación es también aplicable a las referencias entre paréntesis del extremo opuesto del esquema.

39 Al igual que en la referencia al positivismo lógico, estos autores que no hemos tratado tienen grandes diferencias entre ellos. 
cima de las tradiciones específicas y que no se ubicaría en tradición científica alguna. En este punto se acerca a una posición justificacionista y normativa con pretensiones de universalidad. De esta manera el dilema universalismocontextualismo vuelve a plantearse, aunque de manera más moderada.

Probablemente el dilema no sea del todo soluble y siempre exista una tensión entre apego a la historicidad de las tradiciones y reconstrucción de su desarrollo racional en función de criterios epistemológicos y metodológicos.

Pero me parece que podríamos acercarnos más a un punto de equilibrio, que es al final de cuentas como se busca superar el dilema, o al menos disminuir sus costos. Si se toma muy en serio la idea presente en autores como Gadamer, Polanyi, Kuhn y Laudan de que las controversias internas de una tradición y, sobre todo, entre tradiciones distintas son esenciales para el progreso de las tradiciones, me parece que podemos explicar históricamente y evaluar filosóficamente los cambios de tradiciones sin presuponer criterios transhistóricos o universales de racionalidad o de progreso. ${ }^{40}$ Para ello es importante reconocer que las controversias internas y externas cuestionan no sólo los contenidos teóricos, las prácticas y las metodologías de una tradición determinada, sino también sus criterios de racionalidad mismos. Además, es necesario reconocer otra función fundamental de las tradiciones: además de ser fuente de conocimiento, proveer criterios de racionalidad, orientar la selección de hechos relevantes y los procesos heurísticos para la formulación de hipótesis novedosas, las tradiciones constituyen espacios y recursos dialógicos para debatir tanto internamente como con otras tradiciones, y así poder aprender de lo extraño para cuestionar y transformar lo familiar.

Si se considera seriamente esta función comunicativa y pedagógica de las tradiciones podemos olvidarnos de la ansiosa búsqueda de criterios universales y concluyentes para dirimir racionalmente las controversias entre tradiciones sin que este abandono de la ansiedad universalista nos condene al relativismo escéptico. Me parece que la función comunicativa de las tradiciones constituye una base adecuada para dirimir racionalmente no sólo las controversias internas, como lo han señalado Polanyi y Kuhn, sino también los grandes debates entre tradiciones distintas. Tanto Polanyi como Kuhn niegan la posibilidad de soluciones argumentadas y convincentes en

40 En este sentido coincido con la tesis de Marcelo Dascal de que "las controversias son indispensables para la formación, evolución y evaluación de las teorías (científicas) porque es en ellas que se ejerce la crítica seria, es decir aquella que permite engendrar, mejorar y controlar sea la buena estructuración, sea el contenido empírico de las teorías científicas". (Marcelo Dascal, "Epistemología, controversias y pragmática", Isegoría, no. 12 (p. 5 del manuscrito). Veáse también Marcelo Dascal, "La dinámica de las controversias científicas", en Ambrosio Velasco G. (comp.), Racionalidad y cambio científico, Seminario de Problemas Científicos y Filosóficos de la unam-Paidós, México, 1977.) 
las confrontaciones entre tradiciones distintas, reconociendo tan sólo que en estos casos lo que puede suceder es una conversión total al lenguaje y a los presupuestos de una de las tradiciones en conflicto. La prioridad del consenso global parece determinante para reconocer la posibilidad de la argumentación racional. A mi juicio, esta opinión es errónea porque olvida que el disenso es fuente importante de crítica racional. Basta que pueda comprender contenidos y presupuestos ajenos a los de mi propia tradición familiar. Este cuestionamiento no implica la conversión a la tradición ajena y rival, sino simplemente su comprensión. Las críticas potenciales que ofrece la comprensión de tradiciones ajenas abren grandes posibilidades de argumentación racional sea para desechar, o para defender los presupuestos teóricos, conceptuales, ontológicos, metodológicos y epistemológicos de nuestra propia tradición. Como resultado de este diálogo crítico a través de la comprensión de tradiciones diferentes a la propia, se dispondrán de buenas y aún mejores razones para continuar reconociendo la autoridad de ciertos presupuestos de la tradición propia, o bien para revocar esa autoridad y cambiar algunos presupuestos fundamentales.

Entendida de esta manera, la racionalidad inter-tradicional no requiere criterios trans-tradicionales, ni consensos entre tradiciones distintas. Aún más, no se requiere una actitud recíproca entre contendientes de tradiciones distintas. Basta que los representantes de una tradición estén resueltos y comprometidos para comprender $\mathrm{y}$ aprender de otras tradiciones ajenas.

Esta concepción de la racionalidad inter-tradicional guarda semejanzas muy importantes con la idea de Gadamer de la comprensión desde el presente del pasado de una determinada tradición: de la misma manera que los hombres del pasado no dialogan literalmente con el intérprete del presente, es la responsabilidad de este último esforzarse por guardar silencio y escuchar la voz del texto pasado como si fuese un tú, un interlocutor de quien se puede aprender.

En la medida en que el diálogo inter-tradicional, hermenéuticamente fundamentado en la comprensión de tradiciones extrañas, permita una mejor sustentación racional de nuevos y viejos presupuestos de la propia tradición, este tipo de diálogo externo también enriquecerá las controversias internas y promoverá formas argumentativas más convincentes y racionales para dirimir las controversias intra-tradicionales. A su vez estas controversias internas más ricas y las formas argumentativas más racionales ampliarán el horizonte hermenéutico de la tradición para poder comprender mejor tradiciones más distintas y distantes, y así cuestionar de manera profunda los presupuestos de la tradición propia. De esta manera la racionalidad del diálogo inter e intra-tradicional se reforzarán recíprocamente en un círculo virtuoso. 